\title{
Phenotypic switching and filamentation in Candida glabrata
}

\author{
Salil A. Lachke, Sophie Joly, Karla Daniels and David R. Soll \\ Author for correspondence: David R. Soll. Tel: +1 319335 1117. Fax: +1 3193352772. \\ e-mail: david-soll@uiowa.edu
}

Department of Biological Sciences, University of lowa, lowa City, IA 52242, USA

\begin{abstract}
Candida glabrata switches spontaneously, reversibly and at high frequency among the following four phenotypes distinguishable by graded colony colouration on $\mathrm{CuSO}_{4}$-containing agar: white (Wh), light brown (LB), dark brown (DB) and very dark brown (vDB). These phenotypes also differ in a graded fashion in the level of expression of the metallothionein gene MTII (Wh $<$ LB $<$ DB $\leq$ VDB), the frequency of switching (Wh $>$ LB $>D B>V D B$ ) and colouration on phloxine B-containing agar (Wh $>$ LB $>$ DB $>$ vDB). Switching among the four graded phenotypes is referred to as 'the core switching system'. An additional switch phenotype, 'irregular wrinkle' (IWr), has been identified, which exhibits a highly wrinkled colony morphology. The characteristics of IWr suggest that switching to and from this phenotype represents a second high-frequency switching system. A microscopic analysis revealed that during the first 3 days of colony development, cells in the centres of Wh, LB, DB and VDB colonies expressed almost exclusively the budding yeast phenotype. After 3 days, however, pseudohyphae and cells extending tubes accumulated, so that by 7 days the proportions of these two cellular phenotypes reached $\mathbf{4 0 - 5 0} \%$ and $\mathbf{1 0 - 2 0 \%}$, respectively. In contrast, IWr colonies were composed almost exclusively of pseudohyphae through the first 6 days of colony development. After 6 days, IWr colonies began to accumulate both budding yeast cells and tubes. The tubes formed by $C$. glabrata reached lengths of up to six cell diameters, but the tubes did not represent traditional compartmentalized hyphae. Tube growth ended when the tube tip expanded to form a bud. Tubes then functioned as corridors for daughter nucleus migration to the apical bud, and were ultimately left uncompartmentalized and nucleus free. Core switching, pseudohypha formation and tube formation occurred in a majority of 62 tested clinical isolates, demonstrating that these developmental programmes are general characteristics of most strains of C. glabrata.
\end{abstract}

Keywords: Torulopsis glabrata, high-frequency switching, irregular wrinkle switching, pseudohypha formation, tube formation

\section{INTRODUCTION}

Candida glabrata now represents the second most pervasive fungal pathogen behind Candida albicans in most categories of commensalism and infection (Fidel et al., 1999; Hazen, 1995; Lockhart et al., 1999; Odds, 1988; Pfaller et al., 1998). Like C. albicans, it can be carried in a variety of body locations, and can cause superficial mucosal infections as well as bloodstream

Abbreviations: $\mathrm{DB}$, dark brown; $\mathrm{VDB}$, very dark brown; IWr, irregular wrinkled; LB, light brown; Wh, white. infections in compromised hosts (Fidel et al., 1999; Pfaller et al., 1998). Its success is particularly worrisome because it is naturally drug resistant (Berrouane et al., 1999; Fidel et al., 1999; Hazen, 1995; Pfaller et al., 1999; Sanglard et al., 1999, 2001). Epidemiologically, the success of C. glabrata mimics that of C. albicans (Odds, 1988) and for that reason one might expect it to possess similar virulence traits. However, until quite recently it had been generally assumed that C. glabrata lacked two important developmental programmes that contribute to phenotypic variability and, hence, to rapid adaptation of C. albicans, namely high-frequency phenotypic 
switching and the bud-hypha transition. Indeed, the absence of hyphae has been used as a discriminating characteristic in typing C. glabrata (Bale et al., 1997). Believing that both developmental programmes may have been overlooked, we first took advantage of observations that C. glabrata could rapidly alter its resistance to copper by increasing the rate of transcription of metallothionein genes and by amplifying one of these genes, MTII (Mehra et al., 1989, 1990; Zhou \& Thiele, 1991), and developed an indicator agar containing $\mathrm{CuSO}_{4}$, which, when reduced to $\mathrm{CuS}$, causes cells and colonies to turn brown. Plating C. glabrata cells on this agar revealed a spontaneous, reversible, high-frequency switching system that included the following three colony phenotypes: white (Wh), light brown (LB) and dark brown (DB) (Lachke et al., 2000). In an analysis of gene expression, it was further demonstrated that switching in C. glabrata selectively regulated the transcription level of the metallothionein gene MTII in a graded hierarchy similar to that of colouration on $\mathrm{CuSO}_{4}$-containing medium $(\mathrm{DB}>\mathrm{LB}>\mathrm{Wh})$ and the opposite of the hierarchy of switching frequency ( $\mathrm{Wh}>\mathrm{LB}>\mathrm{DB}$ ) (Lachke et al., 2000; Soll, 2002a). These results demonstrated for the first time that C. glabrata, like several other infectious fungi (Enger et al., 2001; Fries et al., 1999; Gil et al., 1990; Goldman et al., 1998; Joly et al., 1996; Odds \& Merson-Davies, 1989; Slutsky et al., 1985, 1987; Soll et al., 1988), undergoes phenotypic switching, and that like switching in C. albicans (Soll, 2002a, b), switching in C. glabrata regulates the expression of selected genes (Lachke et al., 2000). However, in contrast to C. albicans, switching in C. glabrata represents a graded system.

In regard to the bud-hypha transition, Brandao et al. (1995) described the formation of 'germ-like tubes' in three strains of C. glabrata, suggesting that they may be capable of forming hyphae. Odds et al. (1997) identified several apparent Torulopsis species (the previous genus name of C. glabrata) that formed pseudohyphae, and Csank \& Haynes (2000) observed pseudohypha-like projections at the periphery of C. glabrata colonies grown on nitrogen-starvation medium. Together, these results suggested that like C. albicans, C. glabrata is capable of expressing different cellular phenotypes in colonizing populations through both high-frequency phenotypic switching and a dimorphic transition. To understand further the developmental capabilities of C. glabrata, and the relationship between switching and dimorphism in particular, we analysed in more detail the switching repertoire and the relationship of switching and cellular phenotype. From these analyses, we have (1) expanded the core switching system to include four phenotypes distinguishable on $\mathrm{CuSO}_{4}$-containing agar, Wh, LB, DB and very dark brown (vDB), (2) demonstrated that colonies of all four core switch phenotypes produce similar proportions of budding cells, pseudohyphae and tubes during colony development, (3) tentatively identified a second reversible switching system between core phenotypes and an irregular wrinkle
(IWr) colony phenotype that is composed almost exclusively of pseudohyphae, (4) demonstrated that C. glabrata does not form true compartmentalized hyphae, but rather unique, nucleus-free tubes which swell into buds at their apices and then act as corridors for daughter nuclei to access the apical bud, and (5) demonstrated that switching, pseudohypha formation and tube formation represent general developmental characteristics of a majority of 62 tested clinical isolates.

\section{METHODS}

Strain origin and maintenance. The C. glabrata strain used for the basic characterization of switching and filamentation was 35B11, which was isolated from the buccal epithelium of a healthy 65-year-old individual (Lachke et al., 2000; Lockhart et al., 1999). Additional strains used to test the universality of switching and pseudohypha and tube formation were as follows: 32TL10, 29TL1, 32BLWR, 86FL2, 32PL1, 28TL1, 32TL1, 64PL4, 25Pp1, 7549, 39FL5, 65FLOP, 64BLI, 64TL6, 25TLI, 21BLOP, 26BL2, 26TLI, 26B10, 28BL1, 698, 26PL1, 25TL1, 24BL1, 1480.41, 1480.42, 1480.43, 1480.44, 1480.46, $1480.47,1480.48,1480.49,1480.50,86 \mathrm{BL} 1,79 \mathrm{FLOP} 1,79 \mathrm{TL} 1$, 79FL1, 65TL1, 75PL1, 86TL1, 24TL1, 75BL1, J932288, B63155，J932597，J932340，J932285，J931019，J932318, J932273, J932405, J932387, J941814, J932474, J932277, J932436, J942007, J932258/1, J932476, J942283, J932278, J931012. They were obtained from a collection used by Lockhart et al. (1999) in the development of complex DNA fingerprinting probes for C. glabrata (Lockhart et al., 1997) and in an analysis of Candida species colonizing the oral cavities of the very aged (Lockhart et al., 1999). All isolates were initially verified as C. glabrata by sugar assimilation patterns, and then by DNA fingerprinting with the speciesspecific complex DNA fingerprinting probe Cg6 (Lockhart et al., 1997). All clones were stored at room temperature on YPD agar slants $(2 \%$ glucose, $2 \%$ Bacto peptone, $1 \%$ yeast extract, $2 \%$ agar) in capped tubes. Switch phenotypes were grown and propagated on YPD agar plates containing $1 \mathrm{mM}$ $\mathrm{CuSO}_{4}$ at $25^{\circ} \mathrm{C}$ (Lachke et al., 2000). Cells expressing the different switch phenotypes were stored in glycerol at $-80^{\circ} \mathrm{C}$.

Measurements of phenotypic switching. The methods for measuring switching were similar to those previously described in detail (Lachke et al., 2000). In brief, cells from an individual 3-day-old colony exhibiting a homogeneous colony morphology were diluted into YPD liquid medium containing $1 \mathrm{mM} \mathrm{CuSO}_{4}$ and grown for $6-8 \mathrm{~h}$ at $25^{\circ} \mathrm{C}$ to a density of approximately $8 \times 10^{6}$ cells $\mathrm{ml}^{-1}$. Cells were then diluted and plated at a density of approximately 50 c.f.u. per plate. In the case of the irregular wrinkle (IWr) phenotype, cells from a fresh 3-day-old colony were removed from a sectorless region of a colony, diluted and plated at a density of 50 c.f.u. per plate. Plates were incubated at $25^{\circ} \mathrm{C}$ for 5 days, and the numbers of colonies exhibiting the original and variant phenotypes were counted and converted to percentage of population. It should be noted that such frequencies represent the proportions of variant c.f.u. in the original colony, not the rate of switching per cell (Bergen et al., 1990; Rikkerink et al., 1988; Soll et al., 1991). When analysing switching in the absence of $\mathrm{CuSO}_{4}, 5 \mathrm{mg}$ phloxine $\mathrm{B}^{-1}$ was substituted for $\mathrm{CuSO}_{4}$.

Northern analysis of gene expression. Cells from 3-4-dayold colonies were pooled, washed in R Nase-free sterile water and homogenized with acid-washed beads in a bead beater (Bio-spec Products). RNA was then extracted using the RNeasy kit (Qiagen) according to the manufacturer's direc- 
tions, and separated on a $1 \cdot 2 \%$ agarose/formaldehyde gel. RNA was transferred to Zetabind nylon membrane (Amersham Life Sciences) and probed for transcripts of the genes MTII and PDH1 according to methods previously described (Lachke et al., 2000).

Fluorescence microscopy and scanning electron microscopy. Cells were stained for chitin by washing them twice with water, then incubating them in a solution of $0 \cdot 1 \mathrm{mg}$ Calcofluor $\mathrm{ml}^{-1}$ (Cabib \& Bowers, 1975; Hayashibe \& Katohda, 1973) (Florescent Brightener 28, Sigma Diagnostics) for $2 \mathrm{~h}$. Cells were stained for nuclei by first washing them twice in HEPES balanced salt solution (HBSS : $10 \mathrm{mM}$ HEPES, $150 \mathrm{mM} \mathrm{NaCl}$ ). The final pellet was resuspended and cells incubated in $200 \mu \mathrm{l}$ HBSS plus $200 \mu \mathrm{l} 80 \%$ ethanol for $10 \mathrm{~min}$. Hoechst stain (Sigma) was then added to a final concentration of $10 \mu \mathrm{M}$ and the cells incubated in this solution for $20 \mathrm{~min}$. Twenty microlitres of either preparation was pipetted onto a $12 \mathrm{~mm}$ glass coverslip coated with poly-L-lysine and incubated for $10 \mathrm{~min}$. Stained cells were viewed and photographed, first by differential interference contrast (DIC) microscopy and then by epifluorescence microscopy using a UV $365 \mathrm{~nm}$ excitation filter in a Zeiss Axioplan microscope. For presentation of nuclear-stained cells, the DIC and fluorescent images were merged using Adobe Photoshop software. For scanning electron microscopy, cells were rinsed with double-distilled water and distributed on a $12 \mathrm{~mm}$ glass coverslip coated with poly-L-lysine (Sigma Diagnostics). The cells were then fixed for $50 \mathrm{~min}$ in a $2.5 \%$ solution of glutaraldehyde in $0.1 \mathrm{M}$ cacodylate buffer, washed three times in $0 \cdot 1 \mathrm{M}$ sodium cacodylate buffer, postfixed in $10 \% \mathrm{OsO}_{4}$ in $0 \cdot 1 \mathrm{M}$ cacodylate buffer, rinsed in $0 \cdot 1 \mathrm{M}$ cacodylate buffer, and treated with $6 \%$ thiocarbohydrazide to enhance surface architecture. Following a second fixation in $1 \% \mathrm{OsO}_{4}$ to enhance detail, the cells were finally washed in double-distilled water, dehydrated through a graded series of ethanol solutions, dried, mounted on aluminium stubs, and sputter-coated with gold/palladium. Samples were scanned with a Hitachi S-4000 scanning electron microscope.

\section{RESULTS}

\section{Expanding the 'core' switching system to include vDB}

By plating cells of strain 35B11 on agar containing $1 \mathrm{mM}$ $\mathrm{CuSO}_{4}$ at low density, we previously demonstrated that C. glabrata switched spontaneously and reversibly between discrete white (Wh), light brown (LB) and dark brown $(\mathrm{DB})$ colony phenotypes at frequencies ranging from $4 \times 10^{-1}$ to $3 \times 10^{-3}$ (Lachke et al., 2000). The frequencies of switching of the three phenotypes were graded according to the hierarchy $\mathrm{Wh}>\mathrm{LB}>\mathrm{DB}$. This hierarchy was most obvious in the frequencies of sectoring in aged colonies. Two additional colony phenotypes were isolated in the original study (Lachke et al., 2000), very dark brown (vDB) and very white $(\mathrm{vWh})$. Because of their infrequent appearance, neither of these phenotypes was included in the core switching system in the original report (Lachke et al., 2000). In subsequent plating experiments that included larger numbers $\left(\sim 10^{4}\right)$ of $\mathrm{vWh}$ cells, we found no colonies exhibiting the colony phenotypes Wh, LB and DB, and with further incubation, no sectors of the latter three phenotypes. Hence, we conclude that $\mathrm{vWh}$ does not switch reversibly to $\mathrm{Wh}, \mathrm{LB}$ or $\mathrm{DB}$, and, therefore, is not a member of the core switching system. In contrast, in plating experiments of vDB cells $\left(5 \times 10^{4}\right)$, Wh, LB and $\mathrm{DB}$ colonies formed at frequencies of $5 \times 10^{-4}, 8 \times 10^{-3}$ and $5 \times 10^{-4}$, respectively. We therefore conclude that $\mathrm{vDB}$ represents a fourth member of the core switching system (Fig. 1A).

\section{Core switching occurs in the absence of $\mathrm{CuSO}_{4}$}

In addition to graded colouration on agar containing $1 \mathrm{mM} \mathrm{CuSO}_{4}$, the phenotypes of the core switching system can be distinguished by graded colouration on agar containing phloxine B (Fig. 2), a vital dye used previously to discriminate between the white and opaque phases of C. albicans (Anderson \& Soll, 1987). When cells from Wh, LB, DB and $\mathrm{vDB}$ colonies on $\mathrm{CuSO}_{4}$-containing plates were replated at low density on agar lacking $\mathrm{CuSO}_{4}$ and containing phloxine $\mathrm{B}$, the majority of colonies stained dark pink, medium pink, light pink and white, respectively, a hierarchy of pink intensities opposite to the hierarchy of brown intensities on agar containing $\mathrm{CuSO}_{4}$ (Fig. 2A). In Fig. 2(B-D), examples are presented of cells from Wh, LB and DB colonies picked from $\mathrm{CuSO}_{4}$-containing agar plates that were then plated at low density on phloxine Bcontaining plates. The majority of colonies were dark pink, medium pink and light pink, respectively. When cells from dark pink, medium pink, light pink and white colonies on phloxine B-containing agar were replated on agar containing $\mathrm{CuSO}_{4}$, they in turn generated predominantly Wh, LB, DB and vDB colonies, respectively (data not shown), demonstrating that the switch phenotypes originating on $\mathrm{CuSO}_{4}$-containing plates maintained their phenotype in the absence of $\mathrm{CuSO}_{4}$. When cells from a light pink sector and a light pink colony that appeared through switching in a dark pink population were replated on agar containing $\mathrm{CuSO}_{4}$, they formed predominantly DB colonies (Fig. 2B); when cells from light pink to white sectors that appeared through switching in a medium pink population were replated on agar containing $\mathrm{CuSO}_{4}$, they formed predominantly DB colonies (Fig. 2C); and when cells from a medium pink colony that appeared through switching in a light pink population were replated on agar containing $\mathrm{CuSO}_{4}$, they formed predominantly LB colonies (Fig. 2D). Finally, the frequency of switching of the core phenotypes on agar containing phloxine $\mathrm{B}$ was graded dark pink $>$ medium pink $>$ light pink $>$ white. This hierarchy is evident in the frequencies of variant colonies and sectors in the dark pink, medium pink and light pink populations in Figs 2(B), (C) and (D), respectively. This hierarchy was the same as that for switching frequencies observed on $\mathrm{CuSO}_{4}$ (i.e. Wh $>\mathrm{LB}>\mathrm{DB}>\mathrm{vDB}$ ). Together, these results demonstrate that neither core switching nor maintenance of core phenotypes depends on the presence of $\mathrm{CuSO}_{4}$.

\section{The 'irregular wrinkle' switching system}

In expanded plating experiments of LB and DB cells, a new colony phenotype was identified in which the colony dome was irregularly wrinkled, hence the name 


\section{A. Core Switching System}

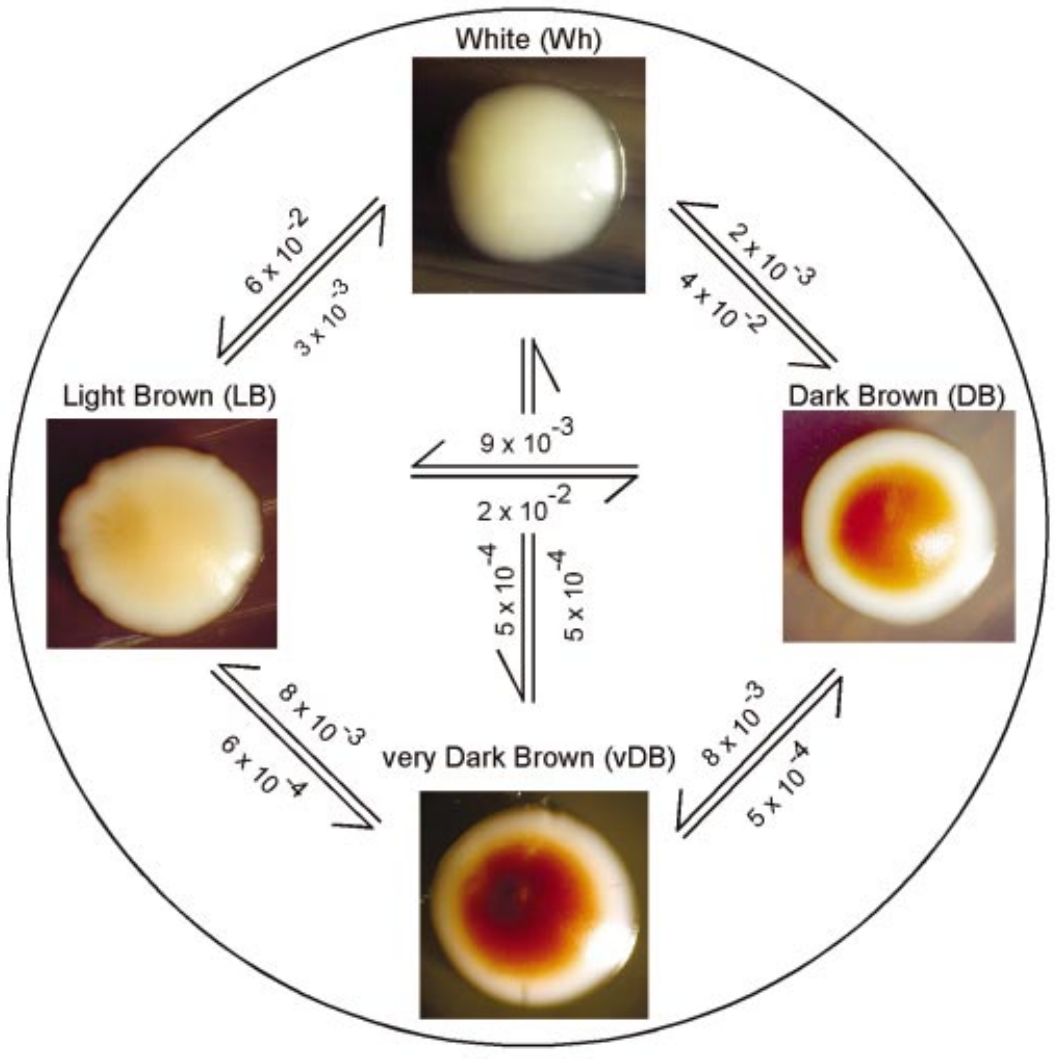

B. Irregular Wrinkle Switching System

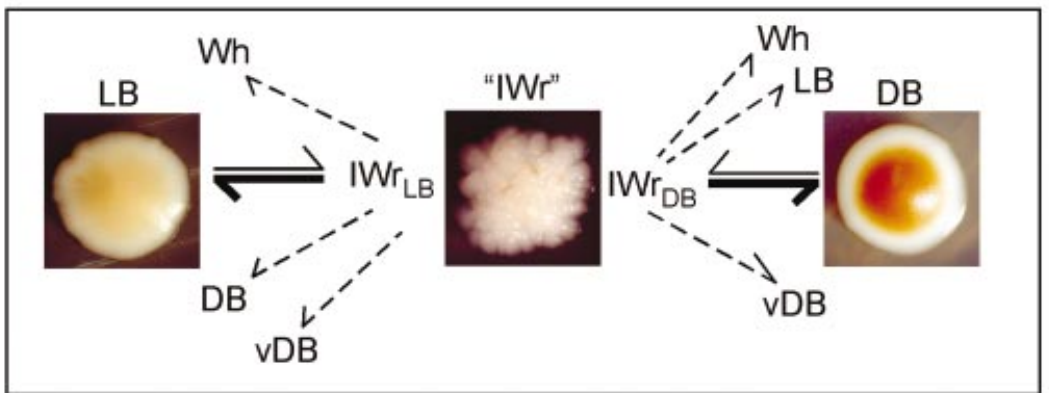

Fig. 1. C. glabrata possesses two switching systems: (A) the 'core switching system', which includes white (Wh), light brown (LB), dark brown (DB) and very dark brown (vDB) phenotypes; and (B) the 'irregular wrinkle (IWr) switching system'. In the latter system, cells switch from a core phenotype to IWr. IWr switches back to a core phenotype, but prefers switching back to the core phenotype of origin. Hence, IWr formed from $L B$ is labelled $I \mathrm{Wr}_{\mathrm{LB}}$, and $\mathrm{IWr}$ formed from $\mathrm{DB}$ is labelled $\mathrm{IWr}_{\mathrm{DB}}$. The frequencies above the arrows in the core switching system refer to the proportions of cells in the phenotype at the base of the arrow that exhibit the phenotype at the head of the arrow. 'irregular wrinkle' (IWr) (Fig. 3A-F). Two independent IWr clones were isolated in LB platings, and five independent IWr clones in DB platings. The frequency at which the IWr phenotype appeared in both the LB and DB populations was approximately $10^{-4}$. The colour of the IWr colonies on $\mathrm{CuSO}_{4}$-containing agar was white to very light brown (Fig. 3A, B) and on phloxine Bcontaining agar dark pink (data not shown). Colonies of the seven independent IWr clones were phenotypically indistinguishable, suggesting that regardless of core phenotype origin, IWr colonies expressed the same colony phenotype.

When cells from IWr colonies were in turn plated on agar containing either $\mathrm{CuSO}_{4}$ or phloxine $\mathrm{B}$, the majority formed IWr colonies, but a sizeable minority (between 2 and $37 \%$ ) switched to core phenotypes, demonstrating a high frequency of reversibility (Fig. 3C, D). When IWr colonies were incubated for more than 7 days, all colonies formed smooth sectors of the core phenotypes (Fig. 3E, F). An analysis of sector phenotypes suggested that IWr cells originating from the LB core phenotype switched preferentially to $\mathrm{LB}$, and that IWr cells originating from the DB core phenotype switched preferentially to DB (Table 1 ). To test this possibility, cells from two independent IWr colonies emanating from LB and two independent IWr colonies emanating from DB were plated, incubated for 10 days, and the phenotypes of sectors scored (Table 1). Because of wrinkling at the colony periphery, it was difficult to 
A.
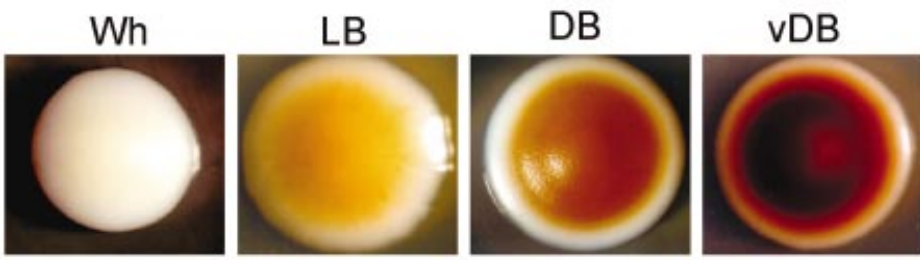

phloxine B
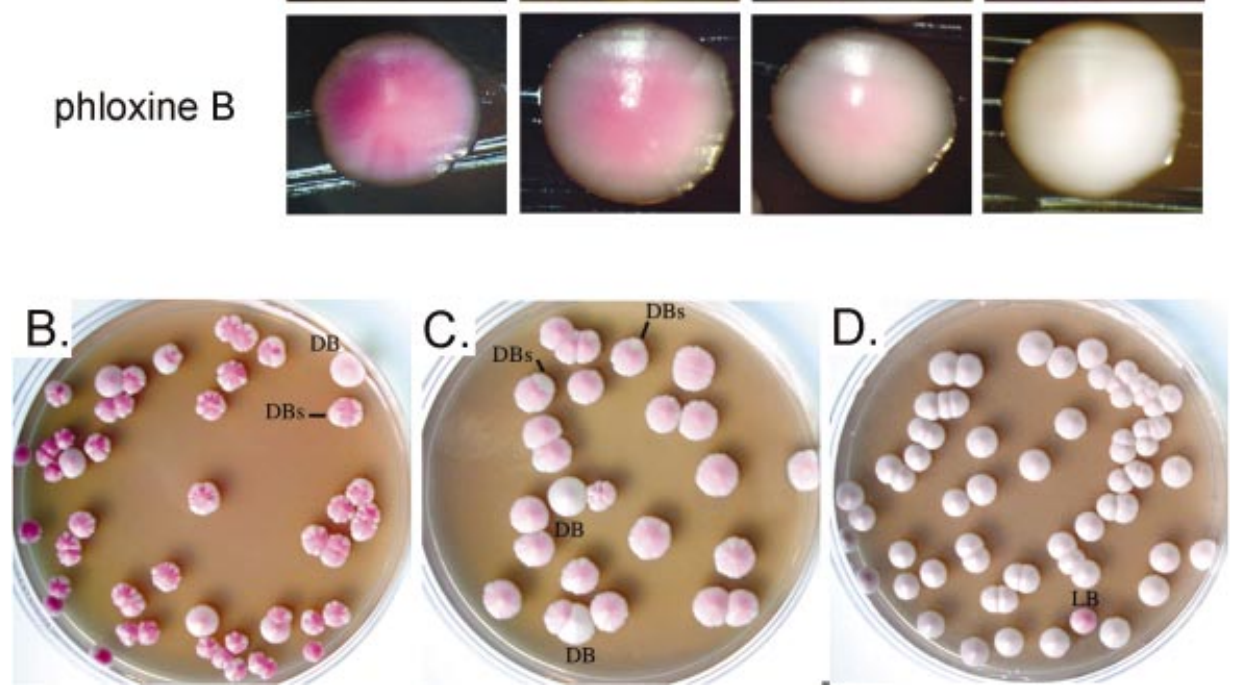

Fig. 2. (A) Whereas $\mathrm{CuSO}_{4}$ stains the core phenotypes white (Wh), light brown (LB), dark brown (DB) and very dark brown (vDB), phloxine $B$ stains the same four core phenotypes dark pink, medium pink, light pink and white. (B-D) Switching occurs on phloxine B-containing agar. When cells from a light pink colony, or a light pink sector formed by dark pink cells (B) or medium pink cells (C) on phloxine B plates were replated on $\mathrm{CuSO}_{4}$-containing agar, they expressed the dark brown (DB) phenotype. When cells from a medium pink colony formed by light pink cells (D) on a phloxine $B$ plate were plated on $\mathrm{CuSO}_{4}$-containing agar, they expressed the light brown (LB) phenotype.

distinguish between Wh and LB sectors, and between $\mathrm{DB}$ and $\mathrm{vDB}$ sectors, so sectors were first scored in the categories Wh/LB and DB/vDB. For both IWr clones obtained from LB, the great majority of sectors $(90 \%$ and $89 \%$, respectively) were Wh/LB, and for both IWr clones obtained from DB, the great majority of sectors $(100 \%$ in both cases) were DB/vDB (Table 1$)$. When cells from 12 randomly selected Wh/LB sectors from IW $r$ clones originating from LB were in turn plated at low density, $75 \%$ formed LB colonies, and when cells from 12 randomly selected $\mathrm{DB} / \mathrm{vDB}$ sectors from IWr clones originating from DB were in turn plated at low density, $100 \%$ formed DB colonies. These results indicate that when cells from different core phenotypes switch to IWr, they retain their original core phenotype identity even though they are morphologically indistinguishable.

Several characteristics suggest that switching to and from IWr represents a phenotypic transition distinct from core switching. First, while IWr cells retain their original core phenotype identity, cells exhibiting core phenotypes do not. For instance, LB cells originating from Wh and DB switch in a similar fashion, showing no preferential switching to $\mathrm{Wh}$ and $\mathrm{DB}$, respectively. Second, IWr colonies, regardless of core phenotype origin, exhibit many characteristics of the Wh core phenotype, including colouration on $\mathrm{CuSO}_{4}$-containing agar, colouration on phloxine B-containing agar, high switching frequencies and, as will be demonstrated, gene expression. Third, IWr does not exhibit a smooth colony dome, a characteristic of all core phenotypes. Fourth, cells in IWr colonies are restricted to the pseudohyphal growth form during the first 6 days of colony development, which is in marked contrast to cells in all core colony phenotypes (see below). Finally, cells in an IW $r$ colony frequently and unpredictably exhibit unusually high reversion rates to their original core phenotype. The unpredictable nature of this reversion suggests that switching from IWr to core phenotype may be far more sensitive to environmental perturbations than core switching phenotypes (data not shown). For these reasons, switching to and from IWr has been tentatively separated into a system distinct from core switching, as described in Fig. 1(B).

\section{Gene expression in VDB and IWr}

In our original description of switching in C. glabrata (Lachke et al., 2000), we demonstrated by slot-blot analysis that the metallothionein gene MTII was expressed in a graded fashion that correlated with the colouration hierarchy on $\mathrm{CuSO}_{4}$-containing agar (Wh $<\mathrm{LB}<\mathrm{DB})$. We also demonstrated that for a majority of tested genes, including PDH1, expression was constitutive and similar in the three core phenotypes 

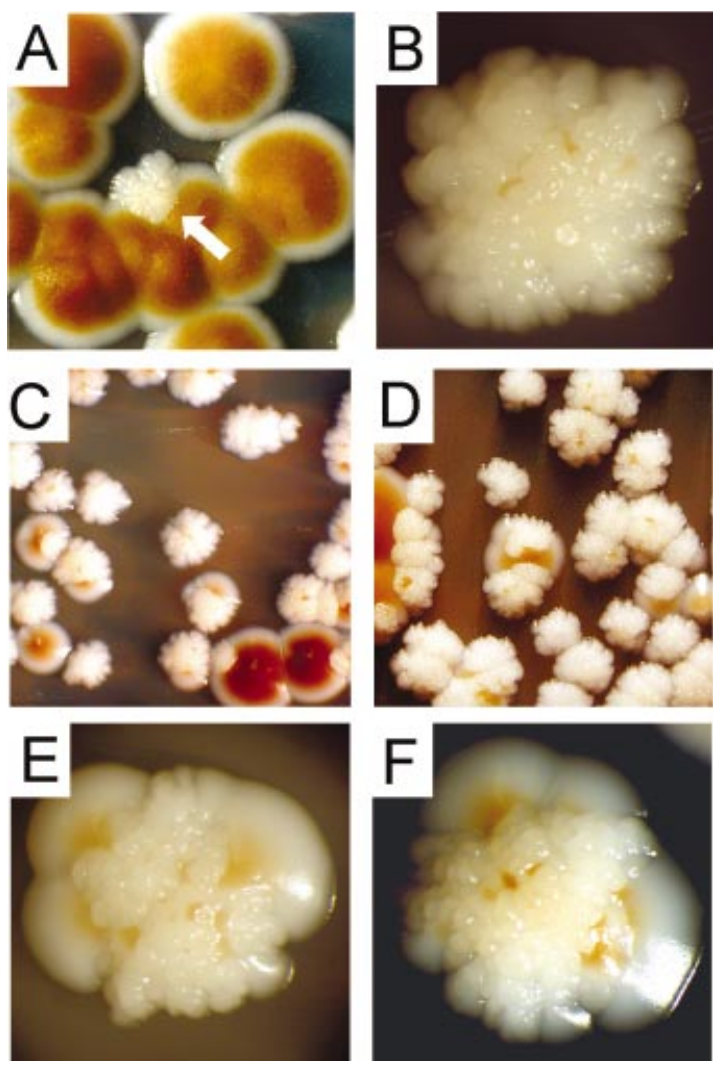

Fig. 3. Dark brown (DB) cells plated on $\mathrm{CuSO}_{4}$-containing agar form irregular wrinkle (IWr) sectors (A, arrow) and colonies (B). When IWr cells are in turn plated, they form predominantly IWr colonies, and switch at high frequency to core phenotype colonies $(C, D)$. When IWr colonies are incubated for extended periods ( $>7$ days), they form sectors expressing core phenotypes (E, F).
(Lachke et al., 2000). If vDB is at the high end of the hierarchy of graded phenotypes in the core switching system, it should also be at the high end of MTII expression. Northern analysis demonstrated that this was indeed the case. In repeat experiments, the level of MTII expression in vDB cells was equal to or slightly higher than that in DB cells (Fig. 4). In contrast, the level of PDH1 expression in $\mathrm{vDB}$ cells was similar to that in Wh, LB and DB cells (Fig. 4). These results support the inclusion of vDB in the core switching system (Fig. 1A). In the case of $\mathrm{IWr}$ cells, colouration on $\mathrm{CuSO}_{4}^{-}$ containing agar, colouration on phloxine B-containing agar and the high frequency of switching together suggest that regardless of core phenotype origin, IWr cells exhibit several of the characteristics of the Wh core phenotype. If this is correct, then IWr cells should express MTII at the low end of the expression hierarchy. Northern analysis demonstrated that this was indeed the case. In repeat experiments the level of MTII expression in IWr cells was similar to that in Wh cells (Fig. 4). In addition, if IWr represents a reversible switch phenotype, then a switch from IWr derived from DB to DB should result in the re-establishment of MTII expression to the same level as that of DB cells. Northern analysis demonstrated that this was indeed the case (Fig. 4). These results support the conclusions that IWr cells exhibit many of the phenotypic characteristics of the Wh core phenotype, and that IWr switches back to bona fide core phenotypes.

\section{Cell morphologies in colonies of the core phenotypes}

In C. albicans, switching between the white and opaque phase involves a dramatic change in cellular morphology (Anderson \& Soll, 1987; Slutsky et al., 1987; Soll, 1992;

Table 1. IWr cells switch preferentially to the core phenotype from which they originally arose

Two IWr clones from LB and two IWr clones from DB were analysed for switching back to core phenotypes. Cells from a 3-day-old colony of each clone were plated and assessed first for the frequency of colonies exhibiting a core phenotype after 7 days. The predominant IWr colonies were then assessed after 7 additional days for the proportion forming sectors and the phenotypes of those sectors.

\begin{tabular}{|c|c|c|c|c|c|c|}
\hline \multirow[t]{2}{*}{$\begin{array}{l}\text { Origin of } \\
\text { IWr clone }\end{array}$} & \multirow[t]{2}{*}{$\begin{array}{l}\text { Clone } \\
\text { no. }\end{array}$} & \multirow[t]{2}{*}{$\begin{array}{l}\text { No. of colonies } \\
\text { analysed }\end{array}$} & \multirow{2}{*}{$\begin{array}{c}\text { Frequency of core } \\
\text { phenotype } \\
\text { colonies" }\end{array}$} & \multirow{2}{*}{$\begin{array}{l}\text { Percentage of IWr } \\
\text { colonies that } \\
\text { form sectors }\end{array}$} & \multicolumn{2}{|c|}{$\begin{array}{l}\text { Percentage of core phenotype } \\
\text { sectors in IWr colonies } \dagger\end{array}$} \\
\hline & & & & & Wh/LB & $\mathrm{DB} / \mathrm{vDB}$ \\
\hline \multirow[t]{2}{*}{ LB } & 1 & 2046 & $10^{-1}(\mathrm{LB})$ & 100 & 90 & 10 \\
\hline & 2 & 2171 & $2 \times 10^{-2}(\mathrm{LB}, \mathrm{DB})$ & 100 & 89 & 11 \\
\hline \multirow[t]{2}{*}{ DB } & 1 & 1256 & $3 \times 10^{-1}(\mathrm{DB})$ & 100 & 0 & 100 \\
\hline & 2 & 1273 & $4 \times 10^{-1}(\mathrm{DB})$ & 100 & 0 & 100 \\
\hline
\end{tabular}

* The frequency of all colonies exhibiting a predominant core phenotype is presented. The major core phenotype is given in parentheses. For LB clone 2, the proportions of LB and DB phenotypes were both $1 \%$.

† When cells from $12 \mathrm{Wh} / \mathrm{LB}$ sectors emanating from IWr clones originating from LB were in turn plated, 9 out of 12 formed LB colonies, 1 formed Wh colonies and 2 formed DB colonies. When cells from $12 \mathrm{DB} / \mathrm{vDB}$ sectors emanating from IWr clones originating from LB were in turn plated, all 12 formed DB colonies. 


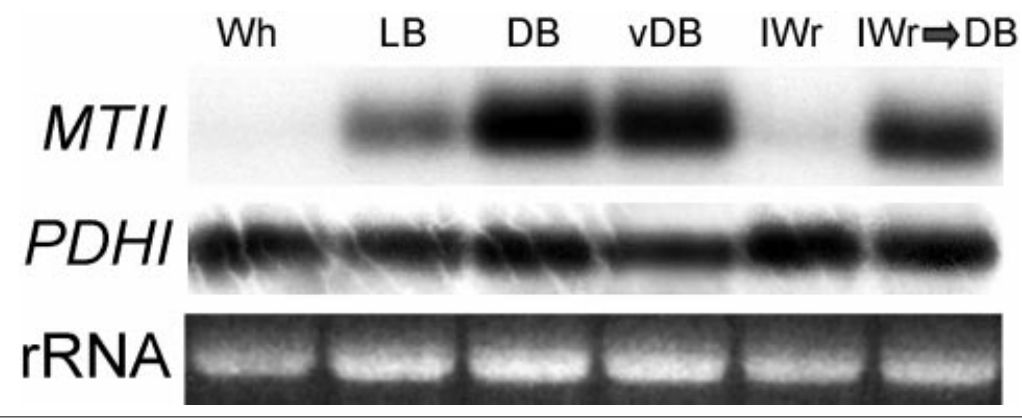

Fig. 4. Northern blot analysis of the expression of the metallothionein gene $(M T I I)$ in $\mathrm{Wh}, \mathrm{LB}, \mathrm{DB}, \mathrm{VDB}, \mathrm{IWr}$, and $\mathrm{IWr}$ that switched to DB. As a control, the same Northern blot was rehybridized with the constitutively expressed gene, $\mathrm{PDH} 1$. To assess loading, the ethidium-bromidestained 26S rDNA band is presented below.
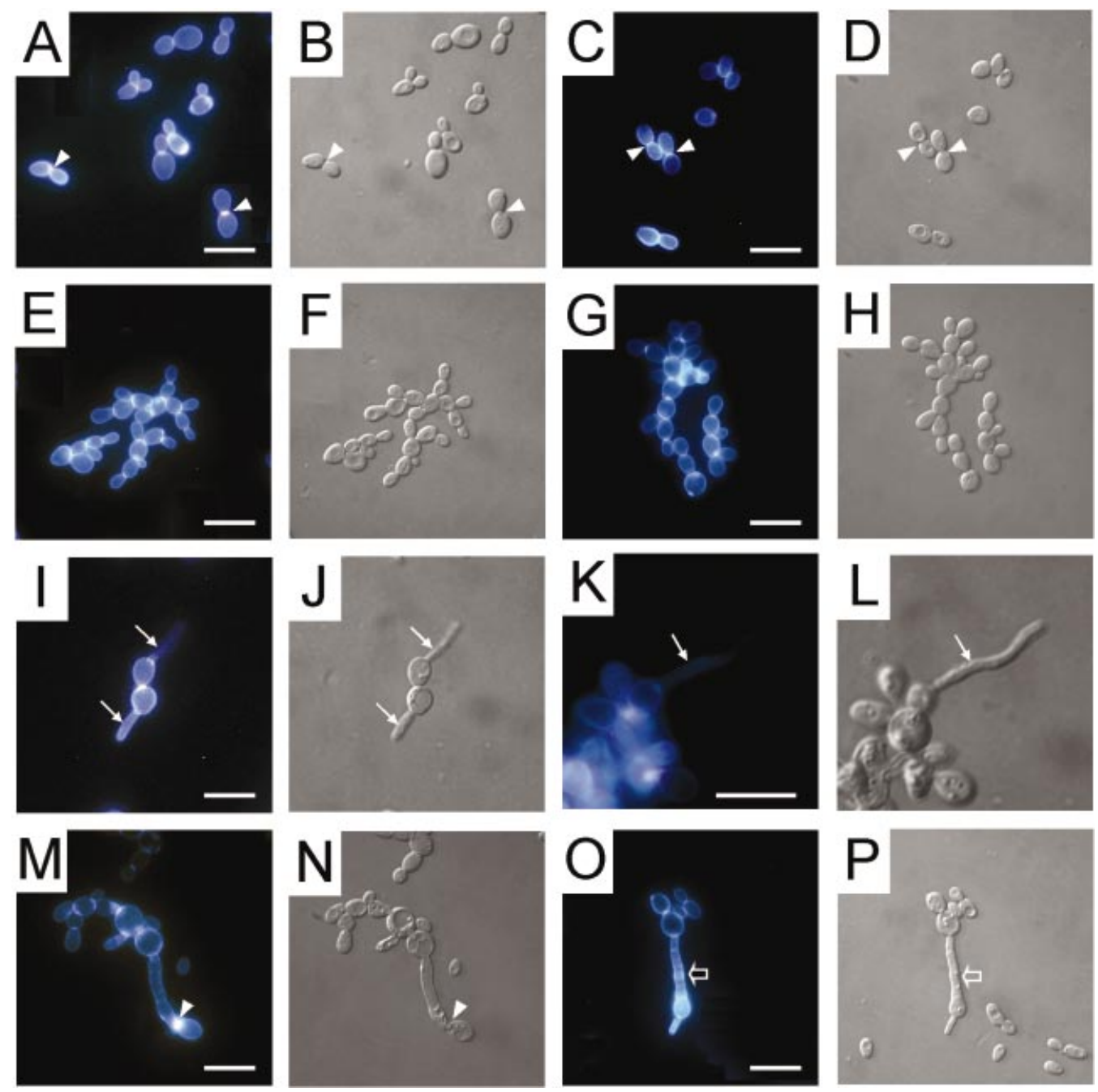

Fig. 5. Chitin distribution and cell morphologies of yeast budding cells (A-D), pseudohyphae (E-H), tubes (I-L) and tubes that have formed or are forming apical buds (M-P). Cells were stained with Calcofluor to visualize chitin-containing septa; fluorescent images are shown in the left panel of each pair. In (A-D), septa between mother and daughter yeast cells are indicated with arrowheads. In (I-L), tubes lacking septa are indicated with arrows. In (M) and (N), the septum separating tube and apical bud is indicated by arrowheads. In $(\mathrm{O})$ and $(\mathrm{P})$, erratic light chitin rings are indicated along expanding tubes by unfilled blunt arrows. Bars, $10 \mu \mathrm{m}$.

Soll et al., 1991). To test whether switching in C. glabrata also affects cellular morphology, samples were removed from the centres of colony domes after 5 days of growth at $25^{\circ} \mathrm{C}$, and examined microscopically. Samples from all of the core phenotypes (Wh, LB, DB, $\mathrm{vDB})$ consisted of approximately $50 \%$ budding yeast 

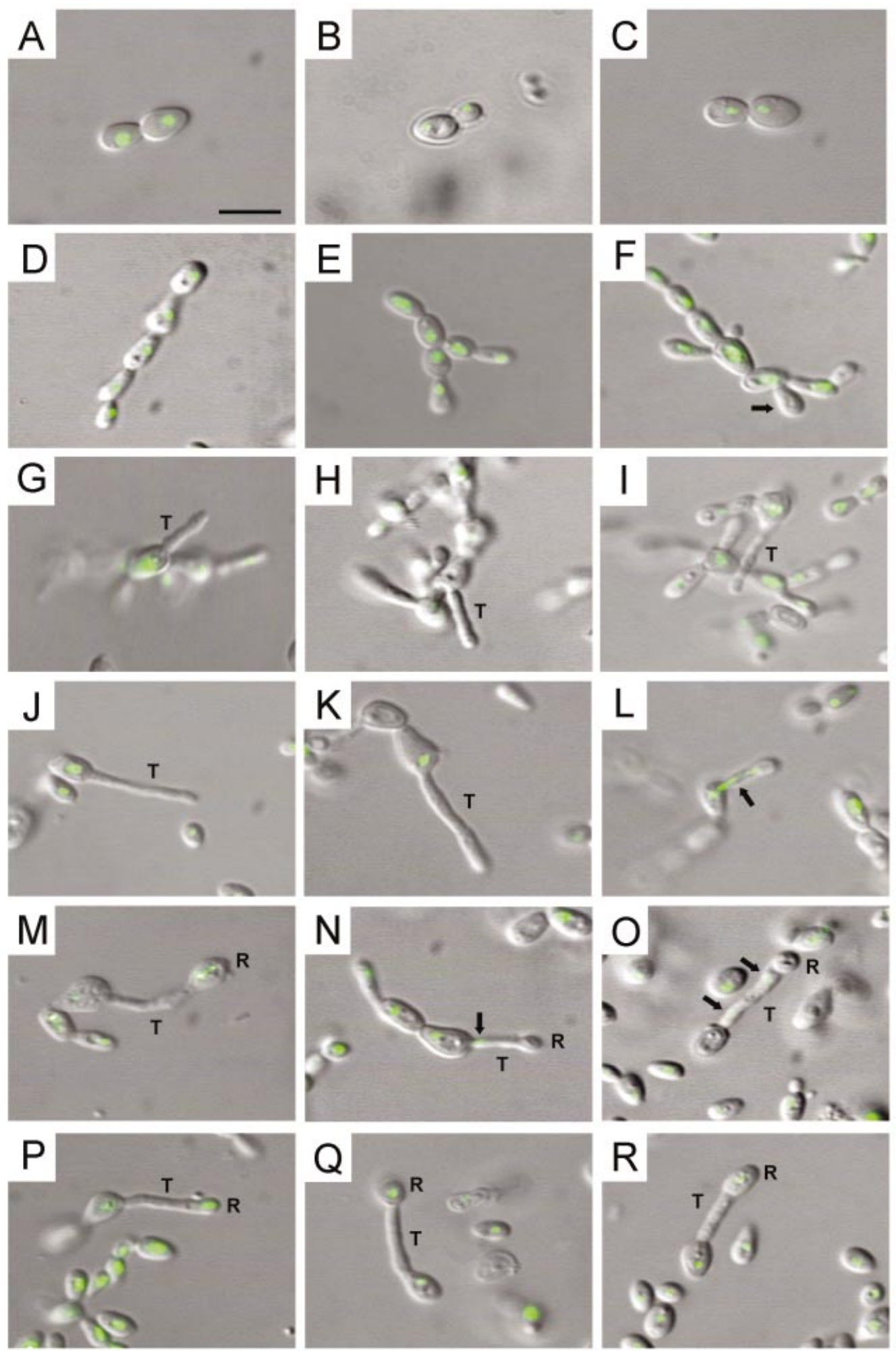

Fig. 6. Nuclear staining of budding cells $(A-C)$, pseudohyphae $(D-F)$, tubes that have not undergone apical expansion $(\mathrm{G}-\mathrm{K})$, and tubes that have undergone apical expansion and apical bud formation (L-R). Cells were stained with Hoechst reagent. The phase-contrast images of the cell and fluorescent images of the nuclei were then merged. Note that tubes $(\mathrm{T})$ that have not undergone apical expansion regardless of length are nucleus free. Tubes undergoing apical expansion can contain elongated nuclei in the process of nuclear division $(\mathrm{L}$, arrowed), or one or both daughter nuclei ( $\mathrm{N}, \mathrm{O}$, arrowed). Cells with developing or complete apical buds contain nuclei in the mother cell and daughter bud, but not in the intervening tube (M, P, Q, R). T, tube; R, apical bud. Bar, $10 \mu \mathrm{m}$. 

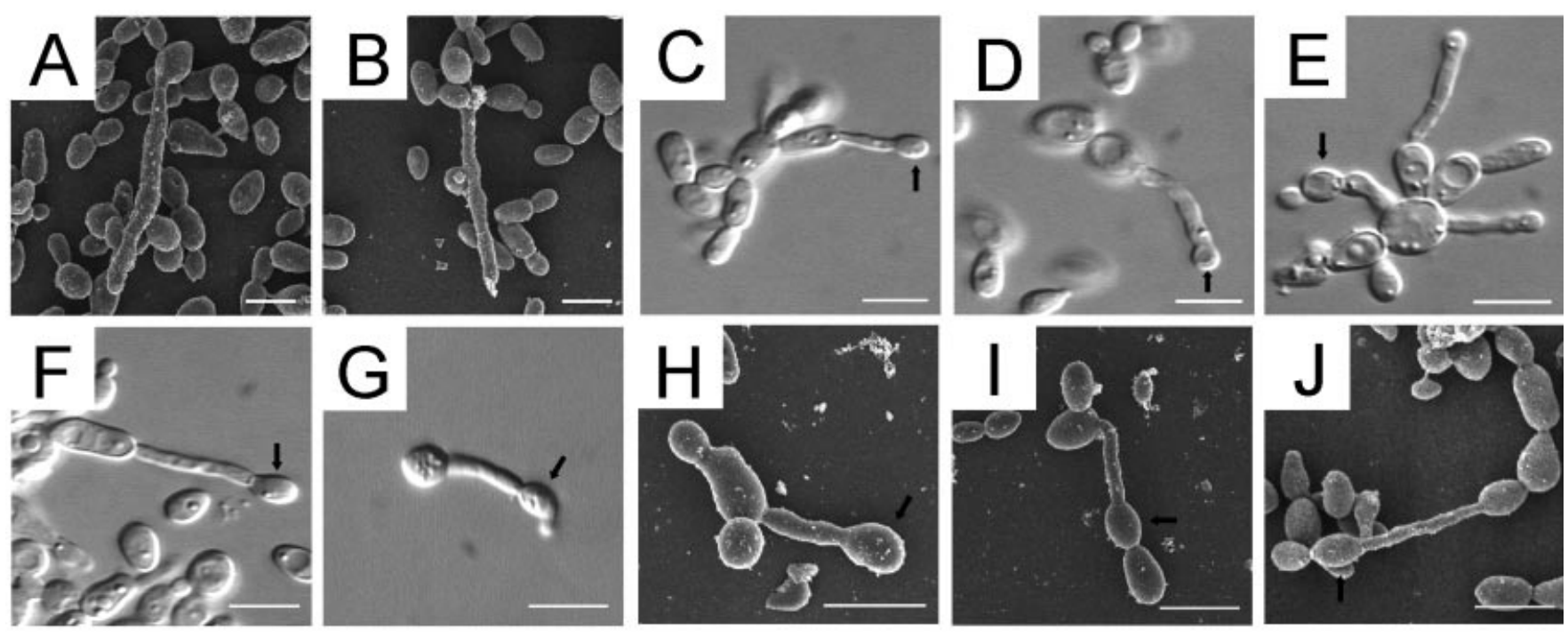

Fig. 7. Scanning electron microscopy $(A, B, H, I, J)$ and phase-contrast $(C-G)$ images of long tubes that have not undergone apical expansion (A, B), tubes undergoing apical expansion (C-E), tubes that have formed distinct apical buds $(\mathrm{F}-\mathrm{H})$, and tubes that have formed apical buds that then grew in the pseudohyphal form (I, J). Arrows indicate apical buds in different phases of growth. Bars, $10 \mu \mathrm{m}$.

cells, $40 \%$ pseudohyphae and $10 \%$ unique tubes. These cellular morphologies are described below.

Budding yeast cells. The budding yeast cells in all four core phenotypes were round to ellipsoidal, and Calcofluor staining revealed chitin-containing septa at mother cell-daughter cell junctions and less intense staining in the general wall (Fig. 5A-D). Budding was primarily axial. The budding yeast cells of the four core phenotypes were morphologically indistinguishable.

Pseudohyphae. Pseudohyphae consisted of ellipsoidal to elongated cells forming chains that were frequently branched (Fig. 5E-H). They conformed to the growth characteristics of pseudohyphae formed by C. albicans (Merson-Davies \& Odds, 1989; Odds, 1988). Calcofluor staining revealed chitin-containing septa at the junctions between compartments and less intense staining in the general cell wall (Fig. 5E, G). All internal cellular compartments in pseudohyphae and large distal compartments contained nuclei (Fig. 6D-F). The pseudohyphae of the four core switch phenotypes were morphologically indistinguishable.

Tubes. Tubes consisted of elongated projections emanating from round or ellipsoidal mother cells (Fig. 5I-P). In the majority of cases, the length of the tube was between one and two mother cell diameters, and the diameter approximately $20 \%$ of the mother cell diameter (Fig. 5I-J). In some cases, tubes grew to lengths up to six times the diameter of the mother cell, with tube diameter roughly one-third the mother cell diameter, as is evident in the scanning electron micrographs (SEMs) in Fig. 7(A, B). In many cases, the apices of tubes expanded into buds, as is evident in both the phasecontrast micrographs in Fig. $7(\mathrm{C}-\mathrm{G})$ and the SEMs in
Fig. $7(\mathrm{H}-\mathrm{J})$. In some cases, the apical bud multiplied in the pseudohyphal growth form (Fig. 7I, J). Narrow tubes that had still not expanded at their apices were completely devoid of chitin septa along their lengths (e.g. Fig. 5I, K). In the case of tubes that had undergone apical expansion, a chitin septum was present at the junction between tube and apical bud (Fig. 5M). In cases in which the tube began to expand erratically prior to apical bud formation, lightly stained chitin rings were evident along the distal portion of the tube preceding the apical bud (Fig. 5O).

Tubes that had not undergone apical expansion were in most cases devoid of a nucleus (Fig. 6G-K). However, tubes that had begun to undergo apical expansion frequently contained two nuclei, one in the mother cell and one in the apical bud, but not along the tube (Fig. $6 \mathrm{M}, \mathrm{P}, \mathrm{Q}, \mathrm{R})$. Occasionally during apical expansion, an elongated nucleus could be found stretched through a portion of the tube, presumably in the process of nuclear division (Fig. 6L), or two daughter nuclei could be found in the tube, presumably just after nuclear division and prior to migration of one back to the mother cell and the other to the apical bud (Fig. 6O). Tube development appeared to be similar in the colony centres of the four core switch phenotypes.

To test whether the proportions of the three cell types differed between the core switch phenotypes during colony development, samples were removed at time intervals from the centres of developing colonies beginning at 3 days, and the proportions of the three cell types computed by microscopic analysis. At 3 days of development, $90-95 \%$ of cells in colonies of the four core phenotypes were in the budding yeast form. The proportion of budding yeast cells then decreased from roughly $90 \%$ at 3 days to $40-50 \%$ at $6-7$ days, followed 


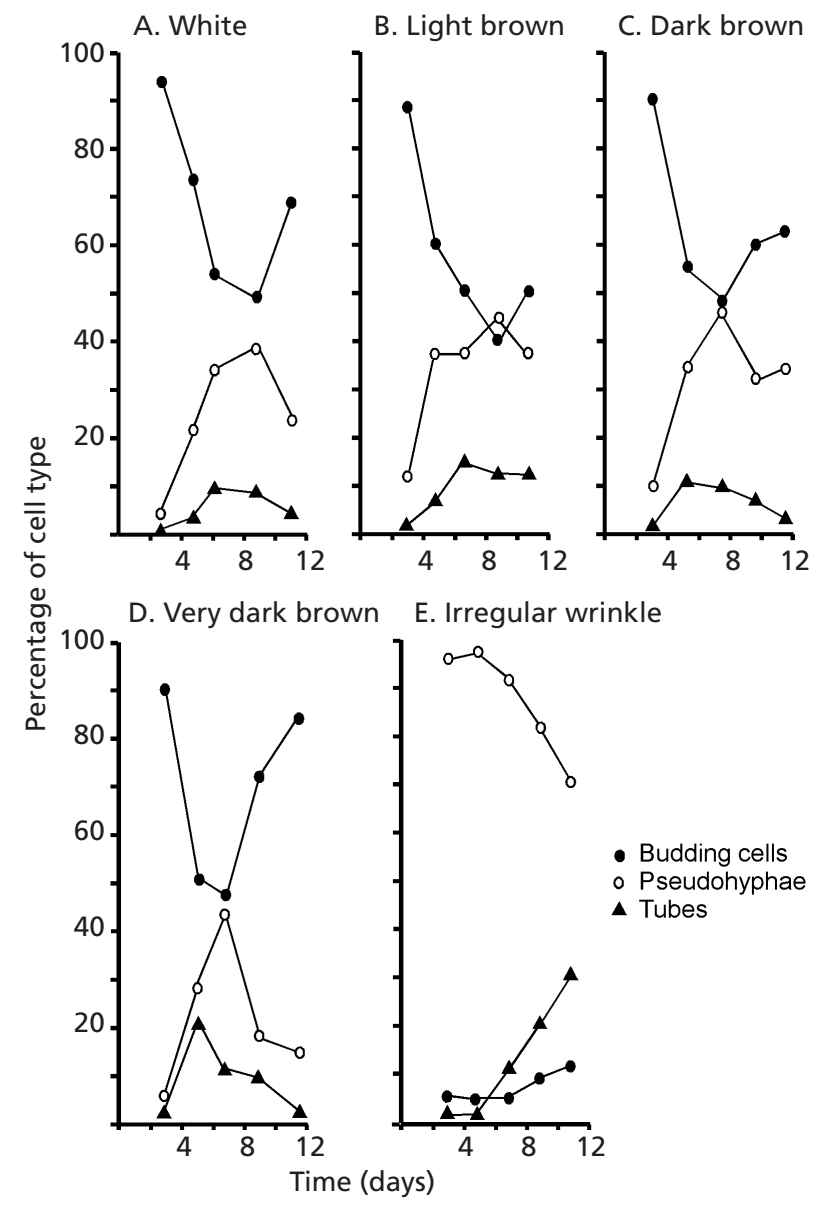

Fig. 8. Proportions of budding cells, pseudohyphae and tubes in the centres of colonies of the different core phenotypes and IWr as a function of colony development time.

by an increase in all four core phenotypes (Fig. 8A-D). The proportion of cells in the pseudohyphal growth form increased from $10 \%$ or less at 3 days to $40-50 \%$ between 7 and 9 days of colony development, and then decreased in all four core phenotypes (Fig. 8A-D). The proportion of tubes increased from less than $2 \%$ at 3 days to $10-20 \%$ between 5 and 6 days of colony development, then decreased in all four core phenotypes (Fig. 8A-D). Pseudohyphae and tubes were also observed in samples taken from colony edges of all four core phenotypes, but the proportions were far lower than in parallel samples taken from colony centres through 11-12 days of development (data not shown). Therefore, the changes in the proportions of budding yeast cells, pseudohyphae and tubes accompanying colony development were similar in the four core phenotypes.

\section{IWr colonies are composed exclusively of pseudohyphae during early development}

During the first 5 days of growth, IWr colonies were composed almost exclusively of pseudohyphae (Fig. 9A-D; Fig. 8E). This was true for samples from the centres as well as the edges of colonies. The morphologies of IWr pseudohyphae were indistinguishable from those formed in the colonies of the core phenotypes. After 6 days of colony development, however, the pseudohyphae in IWr colonies began to form tubes (Fig. 9E, F) and release budding yeast cells. The proportion of budding yeast cells and tubes reached 10 and $30 \%$, respectively, after 11 days of development (Fig. 8E). Therefore, the regulation of cellular phenotype during IWr colony development differs markedly from that during colony development of the core phenotypes, supporting the separation of IWr switching from core switching (Fig. 1).

\section{Switching and filamentation are general characteristics of C. glabrata}

To test whether switching, pseudohypha formation and tube formation represent general characteristics of all strains of C. glabrata, we plated at low density each of 62 independent clinical isolates of C. glabrata on three agar plates ( $\sim 50$ colonies per plate) containing $1 \mathrm{mM}$ $\mathrm{CuSO}_{4}$, and counted the proportions of variant colony phenotypes (i.e. phenotypes other than the dominant phenotype) after 6 days. At the end of 6 days, cells were removed from the centres of representative colonies exhibiting the dominant phenotype and variant phenotypes, and the cell populations (200 cells) scored microscopically for budding yeast cells, pseudohyphae, tubes and tubes with apical expansion. Switching was observed in 25 of the 62 isolates $(40 \%)$. The dominant phenotypes most often expressed by the isolates were DB $(50 \%)$ and LB $(39 \%)$. Of the 25 isolates exhibiting multiple phenotypes in the 200 analysed colonies, $65 \%$ exhibited a mixture of LB and DB, $23 \% \mathrm{LB}, \mathrm{DB}$ and Wh, $4 \%$ Wh and vDB and 4\% LB and Wh. Since only 150 colonies were scored on average for each strain, it was highly likely that switching was missed in many strains with switching frequencies lower than $7 \times 10^{-3}$ (i.e. less than one variant in 150 colonies). We therefore tested whether selected strains forming no variant colonies in the initial plating did so in more expanded analyses (20 plates, providing a sensitivity of 1 in $10^{3}$ colonies). Three strains originally forming only LB colonies and three originally forming only DB were tested. In all cases, switching was demonstrated in the expanded analyses, leading us to conclude that most, if not all, strains of C. glabrata undergo core switching.

Of 93 samples (dominant and variant phenotypes) analysed for cell type, $100 \%$ contained budding yeast cells, $96 \%$ contained pseudohyphae and $85 \%$ contained tubes. Of the samples with tubes, $61 \%$ exhibited expansion at the tube apices. In the cases in which apical expansion was not observed, the frequency of tube formation was usually low. When more cells were examined in two isolates that had a low tube number and no expanded apices in the original analysis, apical expansion of tubes was observed. These results, therefore, indicate that most if not all strains of C. glabrata form both pseudohyphae and tubes, and undergo apical tube expansion. 

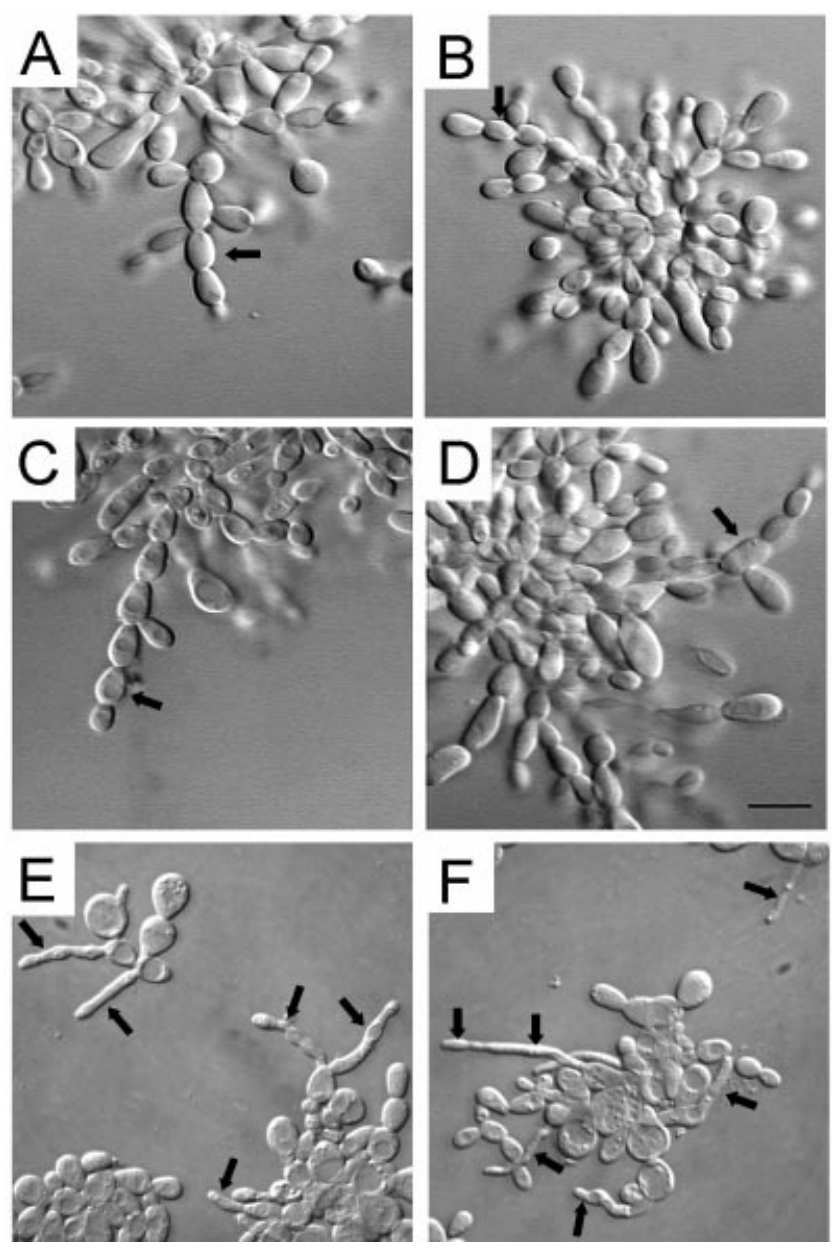

Fig. 9. Phase-contrast images of cells from IWr colonies after 5 days $(A-D)$ and after 12 days $(E, F)$. Arrows indicate examples of the pseudohyphal growth form in the 5-day cultures, and examples of tubes in the 12-day cultures. Bar, $10 \mu \mathrm{m}$.

\section{DISCUSSION}

\section{An updated description of switching in C. glabrata}

By developing an indicator agar containing $\mathrm{CuSO}_{4}$, we initially discovered a spontaneous, reversible, highfrequency switching system in C. glabrata that included the three core phenotypes Wh, LB and DB (Lachke et al., 2000). We also identified in that study two additional phenotypes, $\mathrm{vWh}$ and $\mathrm{vDB}$, which we suggested may be additional members of the same switching system, each at an opposite end of the switching hierarchy (i.e. $\mathrm{vWh}$, Wh, LB, DB, vDB). Here, we have first demonstrated that $\mathrm{vWh}$, which was isolated only once from a DB population, is not reversible and, therefore, does not appear to be part of the core switching system. In contrast, $\mathrm{vDB}$ is reversible, emanating from all other core switch phenotypes, and capable of switching back to all other core switch phenotypes. vDB has, therefore, been incorporated into the 'core' switching system (Fig. 1A) and has been positioned at the upper end of the $\mathrm{CuSO}_{4}$-based colour hierarchy. In support of that decision, we have demonstrated that the expression of the switching-regulated gene MTII in vDB cells is at the high end of the expression hierarchy.

We have also presented proof here that the switch phenotypes discriminated on $\mathrm{CuSO}_{4}$-containing agar maintain their identities in the absence of $\mathrm{CuSO}_{4}$ and that switching between core phenotypes is spontaneous and occurs in the absence of $\mathrm{CuSO}_{4}$. When cells from Wh, LB, DB and $\mathrm{vDB}$ colonies on $\mathrm{CuSO}_{4}$-containing medium were grown on phloxine B-containing agar, they exhibited a hierarchy of opposite intensities (dark pink, medium pink, light pink, white, respectively), and when they were returned to $\mathrm{CuSO}_{4}$-containing agar, they again expressed the phenotypes originally expressed on $\mathrm{CuSO}_{4}$. In addition, when variant colonies and sectors formed on phloxine $\mathrm{B}$ were plated on $\mathrm{CuSO}_{4}$-containing agar, they generated colonies with correlate colours (e.g. white colonies or sectors on phloxine $\mathrm{B}$ formed $\mathrm{DB}$ colonies on $\mathrm{CuSO}_{4}$; medium pink colonies or sectors on phloxine $\mathrm{B}$ formed $\mathrm{LB}$ colonies on $\mathrm{CuSO}_{4}$ ).

\section{Identification of a second switching system in C. glabrata}

In large plating experiments of $\mathrm{LB}$ and $\mathrm{DB}$ cells performed in the present study, we identified a new switch phenotype, IWr, that exhibits several characteristics of the core Wh cell phenotype, including a white to very light brown colour on $\mathrm{CuSO}_{4}$-containing agar, a medium to dark pink colour on phloxine B-containing agar, a low to negligible level of MTII expression, and a very high switching frequency. However, several unique characteristics suggest that switching to and from IWr represents a second switching system. First, unlike all of the core switch phenotypes (Wh, LB, DB, vDB), which form smooth round colony domes regardless of colour, the colony dome of IWr is highly wrinkled, and the perimeter irregular. Second, unlike all of the core switch phenotypes, which are composed of similar proportions of budding yeast, pseudohyphae and tubes, the colony domes of IWr are composed almost exclusively of pseudohyphae through the first 6 days of colony development. Finally, while core phenotypes emanating from different origins (e.g. from LB or DB) then switch to other core phenotypes with similar frequencies, IWr colonies exhibit a distinct propensity to switch back to the core phenotype of origin, suggesting that they maintain their original core phenotype identity. Together these characteristics are more consistent with a model in which switching to and from IWr represents a second spontaneous and reversible switching system.

Although multiple switching systems have been demonstrated previously in C. albicans, the different switching systems have been demonstrated to function in different strains. The switching systems of C. albicans include the '3153A switching system', characterized in strain 3153A (Slutsky et al., 1985) and strain CAI4 (Perez-Martin et al., 1999; Srikantha et al., 1998), the 'white-opaque transition', characterized in strain WO-1 (Slutsky et al., 
1987) and the 'mycelated-unmycelated transition', demonstrated in select isolates from vaginitis patients (Soll et al., 1987). The core and IWr switching systems of $C$. glabrata are the first that have been demonstrated in the same strain and the first that have been shown to interact. To corroborate this model, it must still be demonstrated that Wh and $\mathrm{vDB}$ can generate IWr clones that exhibit the same characteristics as IWr cells emanating from LB and DB, and that switching to and from IWr involves developmental programmes and the expression of phase-specific genes distinct from the programmes and genes involved in and regulated by core switching.

\section{Pseudohypha and tube formation in Wh, LB, DB and vDB colonies}

We have also confirmed previous observations that $C$. glabrata forms pseudohyphae (Csank \& Haynes, 2000) and germ-tube-like structures (Brandao et al., 1995). We have demonstrated here that the centres of 3-day-old colonies of all four core phenotypes contain primarily budding yeast cells, and that during subsequent colony development, colonies accumulate significant levels of pseudohyphae and tubes. We have demonstrated that the formation of pseudohyphae and tubes does not require nitrogen-starvation conditions. The pseudohyphae formed by C. glabrata resemble those formed by C. albicans (Merson-Davies \& Odds, 1989; Odds, 1988). In no case, however, were true hyphae identified. Instead, we observed the frequent formation of tubes, which grew to lengths up to six cell diameters $(9 \mu \mathrm{m})$. These tubes did not compartmentalize like true hyphae (Odds, 1988). Instead, they swelled at their distal ends to form a budding cell or the first in a sequence of pseudohyphal compartments. In cells that formed these tubes, the nucleus divided along the tube, and one daughter nucleus migrated back to the mother cell, while the other entered the apical bud. The C. glabrata tube, therefore, appears to function as a corridor during mitosis through which one daughter nucleus migrates to the new apical bud. Unlike true hyphae such as those found in C. albicans, the tubes of C. glabrata are not compartmentalized and end up nucleus free. It is not unreasonable to suggest that these tubes, like true hyphae, may serve as a vehicle for the dissemination of C. glabrata through tissue. Such a role would be supported by their identification in infected tissue.

\section{Switching and the regulation of cellular phenotype}

Although core switching has no apparent effect on the proportions and morphologies of pseudohyphae and tubes formed in a developing colony, switching to IW $r$ has dramatic effects. During the first 6 days of development, IWr colonies are made up almost exclusively of pseudohyphae. This contrasts markedly with the colonies of all core phenotypes, which are made up predominantly of budding cells at 3 days of development, and slowly accumulate pseudohyphae, which reach a maximum of $40-50 \%$ after 7 days of development. After 6 days, IWr colonies begin to ac- cumulate budding yeast cells and tubes. Switching in C. albicans also affects cellular phenotype. In the whiteopaque transition in C. albicans strain WO-1, cells switch between a round budding cell and an elongated budding cell, phase-specific phenotypes with very different environmental restrictions on the bud-to-hyphae transition (Anderson et al., 1989; Slutsky et al., 1987; Soll, 1992; Soll et al., 1991). In the more complex 3153Atype switching system in C. albicans (Perez-Martin et al., 1999; Slutsky et al., 1985; Soll, 1992; Srikantha, 1998), the differences in colony morphologies reflect dramatic spatial and temporal differences in pseudohypha and hypha formation in the colony dome. Finally, in the unmycelated-mycelated transition (Soll et al., 1987), the difference in colony formation reflects differences in hypha formation at the colony periphery. We may, therefore, suggest that switching in these different Candida species may target similar pathways that regulate filamentation.

\section{Switching and pseudohypha/tube formation are global characteristics of C. glabrata strains}

We originally demonstrated that a single strain of C. glabrata, 35B11, and three additional clinical isolates, 65FLOP, 65TL1 and 75PL1, switched between Wh, LB and DB (Lachke et al., 2000). Here we have demonstrated that in limited plating experiments of 62 additional C. glabrata isolates, $40 \%$ exhibited multiple core colony phenotypes, and in expanded plating experiments of isolates that did not exhibit multiple phenotypes in the initial plating, all formed multiple colony phenotypes; these results lead us to conclude that the great majority of C. glabrata strains undergo core switching. Because of the lower frequency of switching to IWr , an assessment of this switching system in the 62 isolates was untenable. Microscopic analysis of cells from colonies of these 62 isolates also revealed that $96 \%$ formed pseudohyphae and $85 \%$ tubes, and that again these were very likely underestimates, leading us to conclude that in addition to switching, the great majority of C. glabrata strains form pseudohyphae and tubes. Because C. glabrata is related to Saccharomyces cerevisiae (Barns et al., 1991; Santos et al., 1997), and because it is haploid (Doi et al., 1992), the developmental programmes newly established in this pernicious opportunistic yeast pathogen may ultimately be more amenable to analysis than the comparable programmes in diploid C. albicans (Soll, 2000b).

\section{ACKNOWLEDGEMENTS}

This research was supported by NIH grant AI2392 to D.R.S. The authors are indebted to Dr T. Srikantha for his help in the Northern analyses and review of the manuscript.

\section{REFERENCES}

Anderson, J., Cundiff, L., Schnars, B., Gao, M., Mackenzie, I. \& Soll, D. R. (1989). Hypha formation in the white-opaque transition of Candida albicans. Infect Immun 57, 458-467.

Anderson, J. M. \& Soll, D. R. (1987). Unique phenotype of opaque 
cells in the white-opaque transition of Candida albicans. J Bacteriol 169, 5579-5588.

Bale, M. J., Yang, C. \& Pfaller, M. A. (1997). Evaluation of growth characteristics on blood agar and eosin methylene blue agar for the identification of Candida (Torulopsis) glabrata. Diagn Microbiol Infect Dis 28, 65-67.

Barns, S. M., Lane, D. J., Sogin, M. L., Bibeau, C. \& Weisburg, W. G. (1991). Evolutionary relationships among pathogenic Candida species and relatives. J Bacteriol 173, 2250-2255.

Bergen, M., Voss, E. \& Soll, D. R. (1990). Switching at the cellular level in the white-opaque transition of C. albicans. J Gen Microbiol 136, 1925-1936.

Berrouane, Y. F., Herwaldt, L. A. \& Pfaller, M. A. (1999). Trends in antifungal use and epidemiology of nosocomial yeast infections in a university hospital. J Clin Microbiol 37, 531-537.

Brandao, J. C., Verissimo, C., Rosado, M. L. \& Osorio-Almeida, M. L. (1995). Tracing the origin of a Candida albicans infection by pulsed field gel electrophoresis. J Mycol Med 5, 31-34.

Cabib, E. \& Bowers, B. (1975). Timing and function of chitin synthesis in yeast. J Bacteriol 124, 1586-1593.

Csank, C. \& Haynes, K. (2000). Candida glabrata displays pseudohyphal growth. FEMS Microbiol Lett 189, 115-120.

Doi, M., Homma, M., Chindamporn, A. \& Tanaka, K. (1992). Estimation of chromosome number and size by pulse-field gel electrophoresis (PFGE) in medically important Candida species. J Gen Microbiol 138, 2243-2251.

Enger, L., Joly, S., Pujol, C., Simonson, P., Pfaller, M. A. \& Soll, D. R. (2001). Cloning and characterization of a complex DNA fingerprinting probe for Candida parapsilosis. J Clin Microbiol 39, 658-669.

Fidel, P. L., Vazquez, J. A. \& Sobel, J. D. (1999). Candida glabrata: review of epidemiology, pathogenesis and clinical disease with comparison to C. albicans. Clin Microbiol Rev 12, 80-96.

Fries, B. C., Goldman, D. C., Cherniak, R., Ju, R. \& Casadevall, A. (1999). Phenotypic switching in Cryptococcus neoformans results in changes in cellular morphology and glucuronoxylomannan structure. Infect Immun 67, 6076-6083.

Gil, C., Pomes, R. \& Nombela, C. (1990). Isolation and characterization of Candida albicans morphological mutants derepressed for the formation of filamentous hypha-type structures. J Bacteriol 172, 2384-2391.

Goldman, D., Fries, B., Franzot, S., Montella, L. \& Casadevall, A. (1998). Phenotypic switching in the human pathogenic fungus Cryptococcus neoformans is associated with changes in virulence and pulmonary inflammatory response in rodents. Proc Natl Acad Sci U S A 95, 14967-14972.

Hayashibe, M. \& Katohda, S. (1973). Initiation of budding and chitin ring. J Gen Appl Microbiol 9, 23-29.

Hazen, K. C. (1995). New and emerging yeast pathogens. Clin Microbiol Rev 8, 462-478.

Joly, S., Pujol, C., Schröppel, K. \& Soll, D. R. (1996). Development of two species-specific fingerprinting probes for broad computerassisted epidemiological studies of Candida tropicalis. J Clin Microbiol 34, 3063-3071.

Lachke, S. A., Srikantha, T., Tsai, L., Daniels, K. \& Soll, D. R. (2000). Phenotypic switching in Candida glabrata involves phase-specific regulation of the metallothionein gene $M T-I I$ and the newly discovered hemolysin gene HLP. Infect Immun 68, 884-895.

Lockhart, S. R., Joly, S., Pujol, C., Sobel, J., Pfaller, M. \& Soll, D. R. (1997). Development and verification of fingerprinting probes for Candida glabrata. Microbiology 143, 3733-3746.
Lockhart, S. R., Joly, S., Vargas, K., Swails-Wenger, J., Enger, L. \& Soll, D. R. (1999). Natural defenses against Candida colonization breakdown in the oral cavity of the elderly. J Dent Res 78, 857-868.

Mehra, R. K., Garey, J. R., Butt, T. R., Gray, W. R. \& Winge, D. R. (1989). Candida glabrata metallothioneins: cloning and sequence of the genes and characterization of proteins. J Biol Chem 264, 19747-19753.

Mehra, R. K., Garey, J. R. \& Winge, D. R. (1990). Selective and tandem amplification of a member of the metallothionein gene family in Candida glabrata. J Biol Chem 265, 6369-6375.

Merson-Davies, L. A. \& Odds, F. C. (1989). A morphology index for characterization of cell shape in Candida albicans. J Gen Microbiol 135, 3143-3152.

Odds, F. C. (1988). Candida and Candidiasis. London: Baillière Tindall.

Odds, F. C. \& Merson-Davies, L. A. (1989). Colony variation in Candida species. Mycoses 32, 275-282.

Odds, F. C., Rinaldi, M. G., Cooper, C. R., Jr, Fothergill, A., Pasarell, L. \& McGinnis, M. R. (1997). Candida and Torulopsis: a blinded evaluation of use of pseudohypha formation as basis for identification of medically important yeasts. J Clin Microbiol 35, 313-316.

Perez-Martin, J., Uria, J. A. \& Johnson, A. D. (1999). Phenotypic switching in Candida albicans is controlled by a SIR2 gene. EMBO J 18, 2580-2592.

Pfaller, M. A., Jones, R. N., Messer, S. A., Edmond, M. B., Wenzel, R. P. \& Group, S. P. (1998). National surveillance of nosocomial blood stream infection due to species of Candida other than Candida albicans: frequency of occurrence and antifungal susceptibility in the SCOPE Program. Diagn Microbiol Infect Dis 30, 121-129.

Pfaller, M. A., Messer, S. A., Hollis, R. J., Jones, R. N., Doern, G. V., Brandt, M. E. \& Haijeh, R. A. (1999). Trends in species distribution and susceptibility to fluconazole among blood stream isolates of Candida species in the United States. Diagn Microbiol Infect Dis 33, 217-222.

Rikkerink, E. H. A., Magee, B. B. \& Magee, P. T. (1988). Opaquewhite phenotypic transition: a programmed morphological transition in Candida albicans. J Bacteriol 170, 895-899.

Sanglard, D., Ischer, F., Calabrese, D., Majcherczyk, P. A. \& Bille, J. (1999). The ATP binding cassette transporter gene CgCDR1 from Candida glabrata is involved in the resistance of clinical isolates to azole antifungal agents. Antimicrob Agents Chemother 43, 2753-2765.

Sanglard, D., Ischer, F. \& Bille, J. (2001). Role of ATP-bindingcassette transporter genes in high-frequency acquisition of resistance to azole antifungals in Candida glabrata. Antimicrob Agents Chemother 45, 1174-1183.

Santos, M. A. S., Ueda, T., Watanabe, K. \& Tuite, M. F. (1997). The non-standard genetic code of Candida spp. an evolving genetic code or a novel mechanism for adaptation? Mol Microbiol 26, 423-431.

Slutsky, B., Buffo, J. \& Soll, D. R. (1985). High frequency switching of colony morphology in Candida albicans. Science 23, 666-669.

Slutsky, B., Staebell, M., Anderson, J., Risen, L., Pfaller, M. \& Soll, D. R. (1987). 'White-opaque transition': a second high-frequency switching system in Candida albicans. J Bacteriol 169, 189-197.

Soll, D. R. (1992). High frequency switching in Candida albicans. Clin Microbiol Rev 5, 183-203.

Soll, D. R. (2002a). The molecular biology of switching in Candida. In Fungal Pathogenesis: Principles and Clinical Ap- 
plication, pp. 161-182. Edited by R. Cihlar \& R. Calderone. New York: Marcel Dekker.

Soll, D. R. (2002b). Phenotypic switching. In Candida and Candidiasis, pp. 123-142. Edited by R. Calderone. Washington, DC: American Society for Microbiology.

Soll, D. R., Langtimm, C. J., McDowell, J., Hicks, J. \& Galask, R. (1987). High frequency switching in Candida strains isolated from vaginitis patients. J Clin Microbiol 25, 1611-1622.

Soll, D. R., Staebell, M., Langtimm, C. J., Pfaller, M., Hicks, J. \& Rao, T. V. G. (1988). Multiple Candida strains in the course of a single systemic infection. J Clin Microbiol 26, 1448-1459.

Soll, D. R., Anderson, J. \& Bergen, M. (1991). The developmental biology of the white-opaque transition in Candida albicans. In Candida albicans: Cellular and Molecular Biology, pp. 20-45. Edited by R. Prasad. Berlin: Springer.

Srikantha, T., Tsai, L., Daniels, K., Enger, L., Highley, K. \& Soll, D. R. (1998). The two-component hybrid kinase regulator CaNIK1 of Candida albicans. Microbiology 144, 2715-2729.

Zhou, P. \& Thiele, D. J. (1991). Isolation of a metal-activated transcription factor gene from Candida glabrata by complementation in Saccharomyces cerevisiae. Proc Natl Acad Sci U S A 88, 6112-6116.

Received 9 April 2002; revised 10 May 2002; accepted 21 May 2002. 